\title{
Asset Pricing with Idiosyncratic Risk and Overlapping Generations*
}

\author{
Kjetil Storesletten ${ }^{\dagger}$ Chris I. Telmer, ${ }^{\ddagger}$ and Amir Yaron $^{\S}$
}

December 2001

(first draft: June 1996)

\begin{abstract}
Constantinides and Duffie (1996) show that if idiosyncratic labor income shocks (i) are highly persistent, and (ii) become more volatile during economic contractions, the impact on asset prices can be substantial. We argue that life-cycle effects also play a fundamental role. We use a stationary overlapping-generations model to show that life-cycle effects can either mitigate or accentuate the equity premium, the critical ingredient being whether agents accumulate or deccumulate risky assets as they age. Our model predicts the latter and is able to account for both the average equity premium and the Sharpe ratio observed on the U.S. stock market.
\end{abstract}

\footnotetext{
${ }^{*}$ A predecessor of this paper circulated as "Persistent Idiosyncratic Shocks and Incomplete Markets." In addition to numerous participants at seminars and conferences, we thank Dave Backus, Geert Bekaert, David Bowman, Martin Browning, John Cochrane, Wouter den Haan, Mick Devereux, Ron Gallant, René Garcia, Rick Green, John Heaton, Burton Hollifield, Mark Huggett, Narayana Kocherlakota, Per Krusell, Deborah Lucas, Pierre Mella-Barral, Bob Miller, Michael Parkin, Monika Piazzesi, Victor Ríos-Rull, Amlan Roy, Tony Smith, Paul Willen, Steve Zeldes and Stan Zin. for helpful comments and suggestions. We have benefitted from the support of NSF grant SES-9987602 and the Rodney White Center at Wharton. Valuable research assistance was provided by Xiaorong Dong. The current version of this paper is available at http://bertha.gsia.cmu.edu.

${ }^{\dagger}$ Institute for International Economic Studies, Stockholm University and CEPR; storeslk@iies.su.se

${ }^{\ddagger}$ Graduate School of Industrial Administration, Carnegie Mellon University; chris.telmer@cmu.edu

${ }^{\S}$ Wharton School, University of Pennsylvania and NBER; yarona@savage.wharton.upenn.edu
} 


\section{Introduction}

The essence of Mehra and Prescott's (1985) equity premium puzzle is that investing in equity looks like a free lunch; an individual who consumes aggregate consumption places far greater value on the stock market than does the stock market itself. A large literature has asked if aggregation lies at the heart of the puzzle. The idea is that individuals face idiosyncratic risks, are unable to insure against them, and that this affects the way they value financial assets. The plausibility of this story seems apparent; non-financial wealth, human wealth in particular, is subject to substantial risks and is larger in magnitude than financial wealth. Upon closer inspection, however, the story runs into difficulties. Idiosyncratic risks are, by definition, uncorrelated with aggregate risks. In contrast, asset pricing relies on dependence between sources of risk and asset returns in order to explain why some assets pay a higher average return than others. The challenge for a theory of asset pricing driven by idiosyncratic risk, therefore, is to generate such dependence while still having the idiosyncratic shocks wash-out at the aggregate level.

Much of the literature - exemplified by Constantinides and Duffie (1996) and Mankiw (1986) - has overcome this challenge by assuming that aggregate shocks and the volatility of idiosyncratic shocks are negatively related. We begin by examining the quantitative merits of this possibility. We calibrate a version of the ConstantinidesDuffie model based on estimates from the Panel Study on Income Dynamics (PSID), taken from Storesletten, Telmer, and Yaron (2001). We find that by incorporating idiosyncratic risk the risk aversion coefficient required to account for the U.S. Sharpe ratio is 9.4. Absent idiosyncratic risk a value of 34 is necessary. The ConstantinidesDuffie model, therefore, is successful at resolving the equity premium puzzle in the (narrow) sense that, given estimates from labor market data, very high risk aversion is not required.

The Constantinides-Duffie model emphasizes labor income heterogeneity as an important factor for asset pricing. Our paper argues that how labor income heterogeneity varies according to age plays an equally important role. What motivates us is as follows. 'Human wealth' is the value of an individual's future labor income. Our main question - and that of most related work - boils down to whether idiosyncratic shocks to human wealth affect the valuation of financial wealth. The distribution of human wealth necessarily has a life-cycle dimension: the young have more than the old. The same is true, therefore, of idiosyncratic risk. We show that this can be important for asset pricing. Consider, for example, retired people. They comprise roughly 20 percent of the adult population, they participate in equity markets at an even higher rate, yet they face little if any labor market risk. If, as the Constantinides-Duffie model suggests, the solution to the equity premium puzzle is labor market risk which makes equity more risky, then why don't retirees hold all the equity, thus resurrecting the puzzle? 
We address these issues using an overlapping-generations model. The main reason that idiosyncratic risk matters for asset pricing is because it inhibits the intergenerational sharing of aggregate risk. Young agents are endowed with relatively little aggregate risk because (i) most of their wealth takes the form of nontradeable human wealth, and (ii) as is the case in data, aggregate variation in the return to human wealth (i.e., the wage rate) is substantially smaller than equity returns. This suggests an intergenerational transfer of aggregate risk, from the old to the young. Ceteris paribus, such a transfer will tend to reduce the equity premium. Idiosyncratic risk, however, inhibits this transfer. It makes the young less willing to take on aggregate risk and therefore tends to increase the equity premium. The countercyclical-volatility effect emphasized by Constantinides and Duffie (1996) plays an important role, particularly in a quantitative sense. It exacerbates young agents' dislike for aggregate risk and amplifies the effect on the risk premium.

What facilitates intergenerational risk sharing in our model is life-cycle portfolio choice between equity and bonds. The average share of financial wealth held in equity is hump-shaped in age. That is, agents chooses to hold very little equity when young, much more when middle-aged, and relatively little when retired. The reason is essentially the Bodie, Merton, and Samuelson (1992) story, but where labor income risk is incorporated. These authors interpret the 'popular wisdom' of decreasing equity exposure with age as being related to nontradeable human wealth. They point out that if human wealth is riskless, then financial wealth must become less risky as one ages if the risk properties of total wealth are to be maintained. In our model, however, human wealth is anything but riskless. It is subject to idiosyncratic risk which makes the youngest agents - those who face the most idiosyncratic risk - relatively averse to holding equity. It turns what would otherwise be a monotonically decreasing portfolio rule into a hump-shaped one. Such behavior is qualitatively consistent with average portfolio behavior in the U.S. (e.g., Amerkis and Zeldes (2000), Heaton and Lucas (2000)). Our paper represents a model of such behavior driven by idiosyncratic risk. We show that the equilibrium implications can be substantial.

Why don't retirees hold all the equity and resurrect the puzzle? What underlies this question is the notion that if retirees don't face the countercyclical volatility risk which drives the Constantinides-Duffie model, then they will behave like the representative agent and the equity premium will be small. Ceteris paribus, this would be true. Our model gets around it by incorporating the fact that aggregate volatility in equity returns is substantially larger than that in wage rates. This means that a retired agent holding all their wealth in equity would face far more aggregate risk than a (fictitious) representative agent. They choose not to do so because the market-clearing risk premium isn't large enough. What dampens the risk premium is the existence of middle-aged agents whose wealth is partly human and partly financial. Their human wealth makes them less averse than the old to the aggregate risk in equity returns. Their financial wealth makes them less averse than the young to the aggregate risk represented by cyclical volatility in idiosyncratic shocks. They are therefore content 
to hold a levered position in equity and receive a risk premium which induces both the young and the old to diversify into bonds.

Quantitatively, our model is able to account for both the U.S. equity premium and the Sharpe ratio with a risk aversion coefficient of 6.7 . In contrast, our calibration of the Constantinides and Duffie (1996) model requires a coefficient of 9.4 and is unable to simultaneously match both moments. An important caveat is the mechanism with which we generate variability in the return on equity. For computational reasons, we use a production economy with a linear technology and a stochastic depreciation rate. While the consumption side of the model is realistic, the production side is not (investment and output growth are excessively variable).

An advantage of our model relates to risk-sharing behavior. U.S. data on income and consumption indicate that, while complete markets may not characterize the world, neither does a distinguishing feature of the Constantinides and Duffie (1996) framework: autarky. The cross-sectional standard deviation of U.S. consumption, for instance, is roughly 35 percent smaller than that of non-financial earnings. ${ }^{1}$ The Constantinides-Duffie model, in contrast, features consumption and income volatility which are equal. Given the question being asked - How does the market price of risk depend on idiosyncratic risk? - this inconsistency seems of first-order importance. Surely the amount of idiosyncratic risk inherent in consumption allocations must matter? An advantage of our framework is that, even with unit root shocks, allocations feature partial risk sharing behavior. This is a characteristic of how the life-cycle and buffer-stock savings motives interact. Our model generates too little risk sharing (i.e., consumption variability exceeds that of the data). Nevertheless, it suggests that lifecycle effects may help reconcile observed consumption behavior with the high degree of persistence in idiosyncratic shocks which observed asset prices seem to require.

A number of studies have examined the quantitative implications of the Constantinides and Duffie (1996) model. ${ }^{2}$ To understand our contribution, it is important to understand their main result. They show that any given collection of asset price processes are consistent with a heterogeneous agent economy in which agents have

\footnotetext{
${ }^{1}$ A large number of papers, including Altonji, Hayashi, and Kotlikoff (1991), Attanasio and Davis (1996), Attanasio and Weber (1992), Cochrane (1991) Deaton and Paxson (1994) Mace (1991) and Storesletten, Telmer, and Yaron (2000a) provide evidence which is suggestive of imperfect risk sharing. Altug and Miller (1990) find opposing evidence. The numerical value cited here is based upon evidence in both Deaton and Paxson (1994) and Storesletten, Telmer, and Yaron (2000a).

${ }^{2}$ Our paper is also related to a large body of work on asset pricing with heterogeneous agent models. Most closely related is Krusell and Smith (1997), which serves as an important benchmark, both in terms of computational methods and results. Our paper is primarily distinguished by its emphasis on the life cycle. In addition, they require extreme borrowing constraints (essentially zero) in order to generate risk premiums, whereas borrowing constraints play no role in our study. Other related papers include Aiyagari (1994), Aiyagari and Gertler (1991), Alvarez and Jermann (1999), den Haan (1994), Heaton and Lucas (1996), Huggett (1993), Lucas (1994), Mankiw (1986), Marcet and Singleton (1999), Ríos-Rull (1994), Telmer (1993), Weil (1992), and Zhang (1997). The stationary OLG framework we develop owes much to previous work by Ríos-Rull (1994), Huggett (1996) and Storesletten (1999).
} 
'standard' preferences and face idiosyncratic shocks with a particular volatility process. Their model's testable restrictions can be thought of in two ways. First, because the economy admits the construction of a representative agent, it restricts the joint behavior of aggregate consumption, asset returns and the cross-sectional variation in consumption. That is, conditional on knowledge of the cross-sectional variance, the model's first-order conditions can be tested without individual-level data. Papers by Balduzzi and Yao (2000), Brav, Constantinides, and Geczy (2000), Cogley (2000) Ramchand (1999) and Sarkissian (1999) investigate these restrictions and find mixed evidence. Second, if one asks what gives rise to the first-order conditions, the model restricts the joint behavior of individual labor income, asset returns, and individual consumption. Most critical is the requirement that labor income be a unit-root process with innovations which become more volatile during aggregate downturns. Our paper focuses on these restrictions. ${ }^{3}$ The advantages to doing so are both related to data - income is certainly easier to measure than consumption - and the ability to understand how idiosyncratic risk interacts with asset pricing at a structural level.

Finally, the driving force in our model is a concentration of equity ownership on middle-aged agents. The model of Constantinides, Donaldson, and Mehra (1997) shares a similar feature. Where their model is driven by portfolio constraints, however, ours is driven by portfolio choices made in light of how nontradeable and tradeable risks interact. We discuss the testable implications further below.

The remainder of our paper is organized as follows. In Section 2 we formulate a life-cycle version of the Constantinides and Duffie (1996) model, calibrates it, and examine its quantitative asset pricing properties. We then introduce retirement in two steps. First, we assume that the oldest 20 percent of the population do not receive idiosyncratic shocks, but do receive retirement income. This formulation can be studied within the Constantinides-Duffie no-trade framework. Second, we introduce life-cycle savings by assuming that retirement income is equal to zero. Equivalently, we introduce a more realistic distribution of human to financial wealth. This is done in a class of computational economies, with trade, presented in Section 3. Section 4 concludes.

\section{An OLG Version of the Constantinides-Duffie Model}

We begin with a life-cycle version of the Constantinides and Duffie (1996) model. There are two asset markets, a one-period riskless bond and an equity claim to a dividend process, $D_{t}$. The bond and equity prices are denoted $q_{t}$ and $p_{t}$, respectively.

\footnotetext{
${ }^{3}$ Krusell and Smith (1997), emphasize the Constantinides-Duffie model's unrealistic implications for financial wealth distribution. We focus, instead, on its implications for the distribution of financial wealth relative to human wealth. Given the inherent nature of the question - How do nontradeable shocks to human wealth affect the pricing of financial wealth? - this seems of primary importance.
} 
Equilibrium will be autarkic, so limiting attention to two assets is without loss of generality.

The economy is populated by $H$ overlapping generations of agents, indexed by $h=1,2, \ldots, H$, with a continuum of agents in each generation. Agents are born with one unit of equity and zero units of bonds. Preferences are

$$
U(c)=E_{t} \sum_{h=1}^{H} \beta^{h}\left(c_{i t+h}^{h}\right)^{1-\gamma} /(1-\gamma),
$$

where $c_{i t}^{h}$ is the consumption of the $i^{\text {th }}$ agent of age $h$ at time $t$ and $\beta$ and $\gamma$ denote the discount factor and risk aversion coefficients, respectively.

Each agent receives nontradeable endowment income of $y_{i t}^{h}$,

$$
\begin{aligned}
y_{i t}^{h} & =G_{t} \exp \left(z_{i t}^{h}\right)-D_{t}, \quad h=1,2, \ldots,(H-1) \\
y_{i t}^{H} & =G_{t} \exp \left(z_{i t}^{H}\right)-\left(p_{t}+D_{t}\right)
\end{aligned}
$$

where $G_{t}$ is an aggregate shock (defined more explicitly below) and the idiosyncratic shocks, $z_{i t}^{h}$, follow a unit root process with heteroskedastic innovations,

$$
\begin{aligned}
z_{i t}^{h} & =z_{i, t-1}^{h-1}+\eta_{i t} \\
\eta_{i t} & \sim \mathrm{N}\left(-\sigma_{t}^{2} / 2, \sigma_{t}^{2}\right) \\
\sigma_{t}^{2} & =a+b \log \left(G_{t} / G_{t-1}\right) \\
z_{i, t}^{0} & =0
\end{aligned}
$$

This structure is essentially identical to the Constantinides-Duffie formulation, the only exception being that in the last period of life the amount $p_{t}+D_{t}$ is subtracted from income, instead of just $D_{t}$. Equilibrium is autarkic with individual consumption $c_{i t}^{h}=G_{t} \exp \left(z_{i t}^{h}\right)$. Bond and equity prices satisfy

$$
\begin{aligned}
& q_{t}=\beta^{*} E_{t} \lambda_{t+1}^{-\gamma^{*}} \\
& p_{t}=\beta^{*} E_{t} \lambda_{t+1}^{-\gamma^{*}}\left(p_{t+1}+D_{t+1}\right),
\end{aligned}
$$

where $\lambda_{t+1}=G_{t+1} / G_{t}, \beta^{*}=\beta \exp (\gamma(1+\gamma) a / 2)$ and $\gamma^{*}=\gamma-b \gamma(1+\gamma) / 2$ (see Constantinides and Duffie (1996) for derivations). A cross-sectional law of large numbers implies that the variable $G_{t}$, and therefore the growth rate $\lambda_{t}$, coincides with per-capita consumption, which we denote $C_{t}$ (the reason for making a potential distinction will become apparent in the next section),

$$
C_{t}=\frac{1}{H} \tilde{E}_{t} \sum_{h=1}^{H} G_{t} \exp \left(z_{i t}^{h}\right)=G_{t}
$$


where $\tilde{E}_{t}$ is a cross-sectional expectations operator which conditions on time $t$ aggregate information. Since $C_{t}=G_{t}$, the pricing equations (8) and (9) represent a representative agent equilibrium where the agent's preference parameters $\left(\beta^{*}, \gamma^{*}\right)$ are amalgamations of actual preference parameters $(\beta, \gamma)$ and technological parameters $(a$, $b$ ). The main idea behind the Constantinides-Duffie model is that (i) because $\beta^{*}>\beta$, the model may resolve the 'risk-free rate puzzle,' and (ii) if $b<0$ (i.e., the volatility of idiosyncratic shocks is countercyclical) then 'effective' risk aversion exceeds actual risk aversion $\left(\gamma^{*}>\gamma\right)$, and the model may resolve the equity premium puzzle.

\subsection{Calibration}

We now ask if the values of $a$ and $b$ implied by labor market data satisfy the above requirements and help the model account for the equity premium. We use estimates from Storesletten, Telmer, and Yaron (2001) which are based on annual PSID data, 1969-1992. They show that (a) idiosyncratic shocks are highly persistent and that a unit root is plausible, (b) the conditional standard deviation of idiosyncratic shocks is large, averaging 30\%, and (c) the conditional standard deviation is countercyclical, increasing by roughly $120 \%$ from expansion to contraction (from $18 \%$ to $40 \%$ ). In Appendix A we show that these estimates map into values $a=0.038$ and $b=-0.516$.

We use a stochastic process for $\lambda_{t}$ identical to Mehra and Prescott's (1985): a twostate Markov chain with mean, standard deviation and autocorrelation of aggregate consumption growth of $0.018,0.036$, and -0.14 , respectively. We choose the 'effective' discount factor, $\beta^{*}$, to match the average U.S. riskfree interest rate, and the effective risk aversion coefficient, $\gamma^{*}$, to match either the U.S. Sharpe ratio or the unlevered U.S. equity premium. Table 1 reports the implications for the 'actual' risk aversion coefficient, $\gamma$. To match the Sharpe ratio, a value of $\gamma^{*}=34.5$ is required. This corresponds to an actual risk aversion coefficient of $\gamma=9.4$. To match the equity premium $\gamma^{*}=13.9$ is required, which corresponds to $\gamma=5.3$. Time preference is characterized by $\beta^{*}=1.01(\beta=0.16)$ and $\beta^{*}=1.12(\beta=0.61)$, respectively.

The Constantinides-Duffie model, then, is successful at what it sets out to do; given a realistic parameterization for idiosyncratic risk, it accounts for the equity premium without resorting to extreme values for risk aversion and/or negative time preference. Along other dimensions, of course, the model is counterfactual. It generates excessive volatility in both risky and riskless asset returns and cannot account for the ubiquitous rejections of Euler equation tests based on (8) and (9) (i.e., such tests typically reject for all values of $\beta^{*}$ and $\gamma^{*}$ ). Constantinides and Duffie (1996) prove that this can be rectified with an alternative process for the conditional variance $\sigma_{t}^{2}$ from equation (6). The remainder of our paper, however, focuses on a more fundamental set of the model's restrictions, those which involve age and risk sharing. 


\subsection{The Implications of Retirement}

We now introduce retirees and ask to what extent they mitigate the model's success. There are two senses in which the process (2)-(7) does not capture retirement. First, agents face idiosyncratic income shocks in all periods of life. Second, agents receive income each period until death, thus obviating the need to save for retirement. We begin by incorporating the first feature, which can be analyzed in the no-trade environment. The second requires trade and is incorporated in Section 3.

We define a retired agent as one who does not receive an idiosyncratic shock beyond some retirement age so that, for retirees, $a=b=0$. Given this, equations (8) and (9) no longer describe autarkic equilibrium prices. Marginal rates of substitution (at autarky) are

$$
\begin{array}{ll}
\text { workers: } & \beta E_{t}\left(\frac{G_{t+1}}{G_{t}}\right)^{-\gamma} e^{\gamma(1+\gamma) a / 2}\left(\frac{G_{t+1}}{G_{t}}\right)^{\gamma b(1+\gamma) / 2}, \\
\text { retirees: } & \beta E_{t}\left(\frac{G_{t+1}}{G_{t}}\right)^{-\gamma} .
\end{array}
$$

Retirees differ from workers in two ways. First, with $a>0$ the exponential term in equation (10) is positive, implying that retirees discount future consumption more than workers. Intuitively, the absence of idiosyncratic risk reduces their demand for precautionary savings and they assign a lower price to a riskfree bond. Second, if $b<0$, retirees appear less risk averse than workers, assigning a relatively high value to risky assets or, equivalently, demanding a relatively small risk premium. By removing the countercyclical volatility from the retiree's endowments we have effectively given them a greater capacity to bear aggregate risk.

We can now do one of two things to characterize an equilibrium. We can allow trade and solve for market clearing prices to replace equations (8) and (9). This would involve a substitution of consumption from retirement toward the working years, and an increased exposure to aggregate risk for retired individuals. Alternatively, we can follow Constantinides and Duffie (1996) and characterize endowments which give rise to a no-trade equilibrium, but subject to the constraint that retirees do not receive idiosyncratic shocks. The difference between these endowments and those in equations (2) and (3) will be suggestive of what will characterize an equilibrium with trade.

A three-generation example, $H=3$, will make the point. Generations 1 and 2 receive endowments according to equations (2)-(7). Generation 3 - the old agents receive

$$
y_{i t}^{3}=f_{t} G_{t} \exp \left(z_{i t}^{3}\right)-\left(p_{t}+D_{t}\right)
$$

but with $z_{i t}^{3}=z_{i t}^{2}$ (i.e., the innovation in equation (4) equals zero), and

$$
f_{t}=e^{-a(1+\gamma) / 2}\left(\frac{G_{t}}{G_{t-1}}\right)^{-b(1+\gamma) / 2} .
$$


Given the endowment (12), the prices (8) and (9) once again support an autarkic equilibrium. Relative to the original endowment, the old now receive less goods (on average) with more aggregate risk, just as the above intuition suggests. What has changed, however, is aggregate consumption. Assigning a population weight of 20 percent to the old generation (corresponding to the U.S. population), aggregate consumption is

$$
\begin{aligned}
C_{t} & =\tilde{E}_{t}\left(0.8\left[G_{t} \exp \left(z_{i t}^{1}\right)+G_{t} \exp \left(z_{i t}^{2}\right)\right]+0.2 f_{t} G_{t} \exp \left(z_{i t}^{3}\right)\right) \\
& =G_{t}\left(0.8+0.2 e^{-a(1+\gamma) / 2}\left(\frac{G_{t}}{G_{t-1}}\right)^{-b(1+\gamma) / 2}\right)
\end{aligned}
$$

which, because we've added aggregate risk to the endowment of the old, can be substantially more variable than $G_{t}$.

The prices (8) and (9) are now valid, but only in an economy with more variability in aggregate consumption growth than the original. The above calibration (which underlies Table 1) is therefore invalid. Aggregate consumption growth, as implied by equation (13), now has a standard deviation of 9.6 percent, roughly three times larger than U.S. data. In this sense, adding retirees implies that, without changing preferences, the model can only account for asset prices with an unrealistically high amount of aggregate variability.

An alternative is to re-calibrate the process $G_{t} / G_{t-1}$ so that aggregate consumption growth, $C_{t} / C_{t-1}$ from equation (13), has mean, standard deviation and autocorrelation which match the U.S. data. Results are given in the 5th and 6th rows of Table 1. Holding risk aversion fixed, we find that the required reduction in the variability of aggregate consumption growth causes the model's Sharpe ratio to fall from 41.2 percent to 19.7 percent. The equity premium falls from 13.1 percent to 2.9 percent. For the alternative calibration (row 6), the Sharpe ratio and equity premium fall from 23.7 percent to 13.5 percent and 4.1 percent to 1.3 percent, respectively. Finally, if we instead re-calculate the risk aversion coefficient required to match, respectively, the Sharpe ratio and equity premium, we arrive at values of 19.8 and 11.2. Without retirees we required values of 9.4 and 5.3.

To summarize, retirement, defined here as old agents receiving fixed incomes, has the effect one might expect. Because retirees do not face countercyclically heteroskedastic shocks - the driving force in the Constantinides-Duffie model - they are less averse to bearing aggregate risk. An autarkic allocation must therefore skew the aggregate risk toward the old, who are content to hold it in return for a relatively low expected return. In this sense, the incorporation of retirement resurrects the equity premium puzzle. 


\section{Models With Trade}

The previous section emphasized the importance of how idiosyncratic shocks are distributed over the life cycle. Equally important is the distribution of what is being shocked: the human wealth represented by the flow of income, $y_{i t}^{h}$. Human wealth typically accounts for a large fraction of total wealth for young people and a small fraction for older people. Given the nature of our question - How do shocks to human wealth affect the valuation of financial wealth? - incorporating this seems of first-order importance. It may also overturn the implication of the previous section, which was driven by older agents bearing the lion's share of the aggregate risk. If a realistic human/financial wealth distribution reverses this, making the younger agents who face the idiosyncratic risk instrumental in pricing the aggregate risk, the incorporation of retirement may actually help the model to account for the equity premium.

The major cost of incorporating a life-cycle wealth distribution is that, necessarily, we must allow for trade (e.g., if nontradeable income is zero after retirement, the young must save and the old must dissave). With several exceptions, Gertler (1999) for example, this means using computational methods to analyze the model. The benefits, however, are (i) we can make the model more realistic along certain dimensions which are important for calibration (e.g., the demographic structure) and (ii) the model will display partial risk-sharing behavior - an undeniable aspect of U.S. data on income and consumption - even with unit root idiosyncratic shocks. With this in mind, we make the following changes to the framework of Section 2.

\section{Financial markets.}

With trade, the menu of assets is no longer innocuous. We now limit asset trade to a riskless and a risky asset. The latter takes the form of ownership of an aggregate production technology. The main reason for adding production is computational tractability: the resulting price of the risky asset will always be equal to unity. Agents rent capital and labor to a single firm which then splits its output between the two. Labor is supplied inelastically and, in aggregate, is fixed at $N$. Denoting aggregate consumption, output and capital as $Y_{t}, C_{t}$ and $K_{t}$ respectively, the production technology is

$$
\begin{aligned}
Y_{t} & =r_{t} K_{t}+w_{t} N \\
K_{t+1} & =Y_{t}-C_{t}+\left(1-\delta_{t}\right) K_{t} \\
r_{t} & =\theta Z_{t} K_{t}^{1-\theta} N^{1-\theta}-\delta_{t} \\
w_{t} & =Z_{t} w,
\end{aligned}
$$

where $r_{t}$ is the return on capital (the risky asset), $w_{t}$ is the wage rate, $\theta$ is capital's share of output, $Z_{t}$ is an aggregate shock, $w$ controls the average wage rate, and $\delta_{t}$ is 
the depreciation rate on capital. The depreciation rate is stochastic:

$$
\delta_{t}=\delta+\left(1-Z_{t}\right) \frac{s}{\operatorname{Std}\left(Z_{t}\right)}
$$

where $\delta$ controls the average and $s$ is, approximately, the standard deviation of $r_{t} \cdot{ }^{4}$

This production process delivers four key ingredients: (i) the model is tractable (solving the analogous endowment economy is substantially more difficult), (ii) the volatility of the return on equity can be calibrated realistically, (iii) the volatility of aggregate consumption growth can be calibrated realistically, (iv) the return on human capital - essentially the wage rate - can be substantially less volatile than the return on equity. Each ingredient is critical for our question. The first two are obvious. The third ensures that the aggregate part of the asset-pricing Euler equations is realistic (i.e., see equations (8) and (9)), which is essential if we are to isolate the incremental impact of idiosyncratic risk. The fourth is instrumental in determining which age cohorts hold equity in equilibrium and, consequently, whether or not idiosyncratic risk is priced.

These ingredients come at a cost. They imply, for example, excessively volatile investment and output, a feature shared by most existing production-based models should they be calibrated to have realistic variability in asset returns. We do not resolve such issues here. We view our model in the same way we view an endowment economy; as an economy with a potentially unrealistic production side which, nevertheless, yields informative restrictions on consumption and asset returns.

\section{Endowments.}

The endowments (2)-(7) are of a special form required to support an autarkic outcome. Since this is no longer required, and because of the incorporation of production, we reformulate them as follows. First, to capture the fact that young people have relatively little financial wealth relative to human wealth, we endow all newborn agents with zero units of equity and zero units of bonds. Next, the nontradeable endowment now takes the form of labor efficiency units, not units of the single good. ${ }^{5}$ At time $t$ the $i$ th working agent of age $h$ is endowed with $n_{i t}^{h}$ units of labor which they supply

\footnotetext{
${ }^{4}$ Greenwood, Hercowitz, and Huffman (1988) and Greenwood, Hercowitz, and Krusell (1997) have used a similar production technology in a business cycle context. Boldrin, Christiano, and Fisher (2001) have done so in an asset pricing context. Our technology is essentially a reduced-form representation of, for instance, Greenwood, Hercowitz, and Krusell (1997), equation (B3).

${ }^{5}$ Strictly speaking, this is inconsistent with the empirical approach of Storesletten, Telmer, and Yaron (2001) which measured idiosyncratic risk using labor income, not hours worked. To reconcile the two, we have generated simulated data on labor income from our model and estimated a labor income process identical to that in Storesletten, Telmer, and Yaron (2001). Owing in large part to relatively low variability in the wage rate, $w_{t}$, the results were very similar. In this sense, the population moments for labor income in our model have been calibrated to sample moments on nonfinancial income from the PSID.
} 
inelastically. Retirees, agents for whom $h$ exceeds a retirement age $\hat{H}$, receive $n_{i t}^{h}=0$. For workers,

$$
\log n_{i t}^{h}=\kappa_{h}+z_{i, t}^{h},
$$

where $\kappa_{h}$ is used to characterize the cross-sectional distribution of mean income across ages, and

$$
z_{i t}^{h}=\rho z_{i, t-1}^{h-1}+\eta_{i t}, \quad \eta_{i t} \sim \mathrm{N}\left(0, \sigma_{t}^{2}\right)
$$

with $z_{i t}^{0}=0$. For computational reasons, we use a two-state specification for $\sigma_{t}^{2}$ :

$$
\begin{aligned}
\sigma_{t}^{2} & =\sigma_{E}^{2} \text { if } Z \geq E(Z) \\
& =\sigma_{C}^{2} \text { if } Z<E(Z) .
\end{aligned}
$$

Individual labor income now becomes the product of labor supplied and the wage rate: $y_{i t}^{h}=w_{t} n_{i t^{\circ}}^{h}$

With $\rho=1$ this process is analogous to the Constantinides-Duffie process, (2)-(7). The exceptions are that (i) income is now a share of the aggregate wage bill instead of aggregate consumption, (ii) financial income is no longer 'taxed' at 100 percent as in (2)-(7), and (iii) the variance of the innovations to $z_{i t}^{h}$ is now a discrete function of the technological shock $Z$, not a continuous function of aggregate consumption growth.

\subsection{Equilibrium}

The state of the economy is a pair, $(Z, \mu)$, where $\mu$ is a measure defined over an appropriate family of subsets of $S=(\mathcal{H} \times \mathcal{Z} \times \mathcal{A}), \mathcal{H}$ is the set of ages, $\mathcal{H}=\{1,2, \ldots, H\}, \mathcal{Z}$ is the product space of all possible idiosyncratic shocks, and $\mathcal{A}$ is the set of all possible beginning-of-period wealth realizations. In words, $\mu$ is simply a distribution of agents across ages, idiosyncratic shocks and wealth. The existence of aggregate shocks implies that, necessarily, $\mu$ must evolve stochastically over time (i.e., $\mu$ belongs to some family of distributions over which there is defined yet another probability measure). We use $G$ to denote the law of motion of $\mu$,

$$
\mu^{\prime}=G\left(\mu, Z, Z^{\prime}\right) .
$$

The bond price and the return on equity can now be written as time-invariant functions $q(\mu, Z)$ and $r(\mu, Z)$. The wage rate is $w(\mu, Z)$. Omitting the (now redundant) time $t$ and individual $i$ notation, the budget constraint for an agent of age $h$ is,

$$
\begin{aligned}
c_{h}+k_{h+1}^{\prime}+b_{h+1}^{\prime} q(\mu, Z) & \leq a_{h}+n_{h} w(\mu, Z) \\
a_{h} & =k_{h} r(\mu, Z)+b_{h} \\
k_{h+1}^{\prime} & \geq 0 \\
b_{H+1}^{\prime} & \geq 0
\end{aligned}
$$

\footnotetext{
${ }^{6}$ Our model assumes that bequests are zero. This provides focus on our main point: the effect of intergenerational dispersion in the ratio of human to total wealth.
} 
where $a_{h}$ denotes beginning-of-period wealth, $k_{h}$ and $b_{h}$ are beginning-of-period capital and bond holdings, and $k_{h+1}^{\prime}$ and $b_{h+1}^{\prime}$ are end-of-period holdings. The third equation rules out shortselling (which turns out to be innocuous) and the the fourth restricts terminal wealth to be non-zero. Note that, beyond terminal wealth, we do not impose borrowing constraints. Section 3.5 examines the effects of more restrictive assumptions.

Denoting the value function of an agent of age $h$ as $V_{h}$, the choice problem can be represented as,

$$
\begin{gathered}
V_{h}\left(\mu, Z, z_{h}, a_{h}\right)=\max _{k_{h+1}^{\prime}, b_{h+1}^{\prime}}\left\{u\left(c_{h}\right)+\right. \\
\left.\beta E\left[V_{h+1}^{\prime}\left(G\left(\mu, Z, Z^{\prime}\right), Z^{\prime}, z_{h+1}^{\prime}, k_{h+1}^{\prime} r\left(G\left(\mu, Z, Z^{\prime}\right), Z^{\prime}\right)+b_{h+1}^{\prime}\right)\right]\right\},
\end{gathered}
$$

subject to equations (20). An equilibrium is defined as stationary price functions, $q(\mu, Z), r(\mu, Z)$ and $w(\mu, Z)$, a set of cohort-specific value functions and decision rules, $\left\{V_{h}, k_{h+1}^{\prime}, b_{h+1}^{\prime}\right\}_{h=1}^{H}$, and a law of motion for $\mu, \mu^{\prime}=G\left(\mu, Z, Z^{\prime}\right)$, such that $r$ and $w$ satisfy equations (16) and (17), the bond market clears,

$$
\int_{S} b^{\prime}\left(\mu, Z, z_{h}, a_{h}\right) d \mu=0
$$

aggregate quantities result from individual decisions,

$$
\begin{aligned}
K(\mu, Z) & =\int_{S} k_{h}\left(\mu, Z, z_{h}, a_{h}\right) d \mu \\
N & =\int_{S} n_{h} d \mu
\end{aligned}
$$

agents' optimization problems are satisfied given the law of motion for $(\mu, Z)$ (so that $\left\{V_{h}, k_{h+1}^{\prime}, b_{h+1}^{\prime}\right\}_{h=1}^{H}$ satisfy problem (21)), and the law of motion, $G$, is consistent with individual behavior. We characterize this equilibrium and solve the model using the computational methods developed by Krusell and Smith (1997) and described further in Appendix B.

\subsection{Quantitative Properties}

Our model now has three main motives for trade: the life-cycle distribution of idiosyncratic shocks, the life cycle distribution of the ratio of human to total wealth, and the possibility that $\rho<1$. In order to focus on life-cycle issues and maintain a tangible link with the Constantinides-Duffie benchmark, we put the latter aside until Section 3.4 .

We calibrate the above economy according to the criteria outlined in Appendix A. The most important features are as follows. 
1. The standard deviation of aggregate consumption growth matches the annual U.S. sample value of 3.7 percent. As equations (8) and (9) emphasize, realistic properties for aggregate consumption are essential here, just as they are in representative agent models. The cost, in our case, is excessively volatile output and investment, something which is commonplace in models with production. Full details are provided in Appendix A.

2. The standard deviation of the return on capital matches the annual sample moment of 10 percent from the unlevered CRSP value-weighted index. This is achieved in a reduced-form manner, via the stochastic depreciation process (18). We therefore have little to say about why the return on the equity market is as variable as it is. What we can say, however, is that the main consequence the return on financial capital being substantially more volatile than the return on human capital - has stark implications for life-cycle portfolio choice and, therefore, for how idiosyncratic shocks interact with asset pricing. ${ }^{7}$

3. Idiosyncratic risk, captured by equation (19), follows a unit-root process with a regime-switching conditional variance function chosen to match the estimates in Storesletten, Telmer, and Yaron (2001). Their estimate of $\rho$ is 0.92 . We scale down the variances in our model so that, with $\rho=1$, the unconditional variance over the life-cycle matches that implied by their $\rho<1$ estimates. This results in $\sigma_{E}=0.0977$ and $\sigma_{C}=0.2161$.

4. Young agents are born with zero assets and retired agents receive zero labor income. This serves as the primary motive for trade. It also results in a realistic life-cycle distribution of human to financial capital - younger agents hold most of the former whereas older agents hold most of the latter - which, as we'll see, plays an important role in portfolio choice.

5. Retired agents comprise roughly 20 percent of the population.

Table 1 reports the first two moments of the asset returns in this economy. In order to match the observed U.S. Sharpe ratio and mean equity premium, our model requires a risk aversion coefficient of $6.7 .^{8}$ In contrast, the Constantinides-Duffie model with retirement, where retirement simply means not facing idiosyncratic risk (Section 2.2), requires a coefficient of 19.8. The incorporation of life-cycle savings, therefore, more than offsets the negative effect of retirees not receiving shocks. More generally, our

\footnotetext{
${ }^{7}$ A potentially important counterfactual aspect of our economy is that the return on capital is far more correlated with the wage rate - and therefore with labor earnings - than we see in the data. This can be overcome, at a non-trivial computational cost, by making the depreciation process (18) a stochastic function of the technology shock $Z$.

${ }^{8}$ Interestingly, this value for risk aversion is similar to what Cogley (2000) finds using CEX data in a model with time-varying cross-sectional moments. He estimates risk aversion of 8 with 6.7 lying well within a $90 \%$ confidence interval.
} 
model also requires lower risk aversion than the Constantinides-Duffie model without retirement: a coefficient of 6.7 versus one of 9.4. The overall effect of the life cycle, then, is one of magnifying the effect of idiosyncratic risk on asset pricing.

To understand this, consider the portfolio behavior depicted in Figure 1. The figure reports the fraction of financial wealth invested in bonds for the mean individual of each age. We see that the youngest agents choose to hold only bonds. Agents between age 29 and 43 and those older than 63 tend to hold diversified portfolios of bonds and equity. Finally, mature workers - those between age 43 and 63 - issue bonds, thus maintaining a levered position in equity. There are two main forces at work:

(i) The youngest workers face the most idiosyncratic risk and, therefore, are relatively ill-equipped to bear aggregate risk. More specifically, the young hold almost all of their wealth as human wealth, which is directly subject to idiosyncratic shocks. These shocks are large and they persist over much of a young agent's life. Moreover, their volatility covaries negatively with the risky return, something which discourages risky asset holding for any working agent. Because this is particularly true for the youngest workers, in equilibrium they choose to hold no risky assets whatsoever (recall that shortselling is prohibited).$^{9}$

(ii) Retired agents are also relatively ill-equipped to bear aggregate risk, but for a different reason. Retirees must finance consumption entirely out of financial wealth. Aggregate variation in the return on equity is large relative to that of human wealth. ${ }^{10}$ A retiree holding all of their wealth as equity, therefore, would face substantially more aggregate risk than would a worker holding all of their financial wealth as equity, because the worker also owns some human wealth. The result, as we see in Figure 1, is that retirees choose to diversify and allocate some of their wealth toward bonds. These bonds are issued by mature workers. ${ }^{11}$

Young workers, then, dislike the risky asset because of the countercyclical nature of the idiosyncratic risk they face. Retirees dislike it because it has a highly variable return

\footnotetext{
${ }^{9}$ This interpretation is confirmed by experiments in which the volatility of idiosyncratic shocks is constant. In this case, the bond portfolio share profile is monotone increasing, as in Jagannathan and Kocherlakota (1996).

${ }^{10}$ To see this, note that our production technology implies that the correlation of the wage rate and the return on capital is essentially unity, with the latter being substantially more variable than the former. Given this, and assuming, for simplicity, that hours worked are an i.i.d. process, it is easily shown that the return on human capital is a convex combination of the return on the bond and the return on capital, where the weight on the capital return is $H^{-1} \times \operatorname{Stdev}(W) / \operatorname{Stdev}(R)$, with $H$ denoting the value of human capital, $W$ denoting the wage rate and $R$ denoting the return on capital. Consequently, the variability of the return on human capital will be small insofar as (i) the variability of $W$ is small relative to that of $R$ and (ii) the size of $H$ is large. The former is a feature of our economy, whereas the latter is increasingly the case, the younger is an agent.

${ }^{11}$ This interpretation is confirmed by experiments in which the return on equity is calibrated to be less than that of the wage rate. In these cases, we observe retired agents holding levered positions in the risky asset and an average bond share which is monotone increasing with age.
} 
and they no longer receive labor income. What Figure 1 shows is that middle-aged workers represent a bridge between the two; they dislike aggregate risk for the same reasons, but in each case to a lesser degree. They hold part of their wealth as financial wealth and therefore care less than the young do about idiosyncratic shocks. They face the same variability in equity returns as the old, but their labor income mitigates their overall exposure to aggregate shocks. The end-result is that the middle-aged hold levered equity by issuing bonds to the young and the old. The resulting hump-shaped pattern in equity ownership is broadly consistent with U.S. data and has been the focus of recent work by Amerkis and Zeldes (2000) and Heaton and Lucas (2000). ${ }^{12}$

This outcome has a natural interpretation in terms of the intergenerational redistribution of aggregate risk. Because the return on capital is more variable than the aggregate component of the return on labor, an efficient allocation will feature aggregate risk being transferred from retirees - those who receive none of labor's share of output - to workers. One mechanism which achieves this is retirees holding bonds which are issued by workers. (e.g., Ríos-Rull (1996)). Young workers, however, face an additional source of aggregate risk, manifested in the conditional variance of their idiosyncratic risk process. ${ }^{13}$ An efficient allocation, therefore, will stop short of transferring aggregate risk to the youngest, resulting instead in the U-shaped pattern we see in Figure 1.

Finally, understanding asset pricing in our economy is straightforward. The essence of Section 2.2 was that if retired agents hold most of the aggregate risk, then, because they face no idiosyncratic risk, the implications of countercyclical volatility may be strongly mitigated and the equity premium puzzle may be resurrected. What we find here is that the life-cycle savings effect - most importantly, the fact that older agents derive most of their income from financial assets - counteracts this, essentially because of the life-cycle distribution of aggregate risk. Aggregate risk motivates retirees to hold a diversified portfolio and, because the young choose a corner solution, the lion's share of the aggregate risk falls on the backs of the middle-aged. These agents are workers and the countercyclical variance in their idiosyncratic shocks matters for risk premia, just as it does in Constantinides and Duffie (1996). How much it matters is a quantitative question, depending mainly on middle-aged agents' ratio of human to total wealth as well as their relative size in the population distribution. The ability to answer this question, as we do in Table 1, is the main benefit of undertaking our computational exercise.

\footnotetext{
${ }^{12}$ Brown (1990) shows that non-tradeable labor income can generate hump-shaped portfolio rules in age. Amerkis and Zeldes (2000) discuss a similar phenomenon. Our computational solution also features hump-shaped decision rules (with age) for the share of financial wealth held as bonds. The cross-sectional average in Figure 1 inherits this shape because financial capital's share of total wealth is, on average, an increasing function of age.

${ }^{13}$ In Storesletten, Telmer, and Yaron $(2000 \mathrm{~b})$ we examine the welfare consequences of this form of aggregate risk more explicitly. We find that the welfare costs of business cycles can be quite large, should the elimination of business cycles also imply the elimination of heteroskedasticity in idiosyncratic shocks.
} 


\subsection{Risk Sharing}

An counterfactual implication of the Constantinides and Duffie (1996) model is that the equilibrium features no risk sharing while the bulk of the existing evidence suggests that partial risk sharing better characterizes the world. This seems important for the question, which essentially asks how idiosyncratic consumption risk affects the market price of risk. Surely the magnitude of the consumption risk which agents face - a synonym for the degree of partial risk sharing — is relevant for this question?

An advantage of the life-cycle model is that, even with unit root shocks, allocations exhibit partial risk sharing. The reason involves the way in which the life-cycle savings interacts with 'buffer-stock savings:' the savings reaction to an unexpected shock. In our model, provided that financial wealth is positive, the marginal propensity to save out of current income is increasing in the level of current income but decreasing in the level of wealth. The implication is that, in spite of being characterized by unit-root shocks, our economy displays a type of contingent, self-insurance behavior.

The risk-sharing behavior of our model is depicted in Figure 2. Panel A shows that, with the exception of the youngest, the cross-sectional variance in consumption is less than that of income. Averaged over age, consumption is roughly 10 percent less variable (in terms of the standard deviation). In U.S. data, this value is roughly 35 percent (see Deaton and Paxson (1994) or Storesletten, Telmer, and Yaron (2000a)), so our model exhibits too little risk sharing. Panel B reports the cross-sectional variance in the growth rate of consumption, which is more directly related to the essence of risk sharing: the equalization of marginal rates of substitution. In this case, we see a larger difference between our model and the autarkic outcome. Autarky implies that, for workers, the graph is flat at 0.17 , as shown. Our model features a monotonically decreasing graph, starting at roughly autarky and falling to near zero. The main reason is what we've emphasized above: a decreasing ratio of human to total capital and the resulting mitigation of the impact of idiosyncratic shocks. Risk sharing behavior is yet another dimension of our model for which this ratio is the main economic force at work.

\subsection{Mean-Reverting Idiosyncratic Shocks}

We assumed $\rho=1$, mainly to provide a coherent link to the Constantinides-Duffie model and isolate the effects of retirement/life-cycle savings. The estimate of Storesletten, Telmer, and Yaron (2001), however, is $\rho=0.92$. We are able to solve economies with mean-reverting shocks, although the computational burden increases substantially. We find that the U-shaped pattern in life-cycle portfolio holdings (see Figure 1 ) is robust to $\rho=0.92$. The main economic message of our paper, therefore, does not rely on unit-root shocks. Quantitatively, Table 1 shows that, holding risk aversion fixed, the equity premium and Sharpe ratio increase slightly relative to the unit-root 
economy. The riskfree rate, however, is -0.50 percent and the variability of aggregate consumption growth is 6.7 percent, roughly double that of our main model. Were we to re-calibrate the model to reconcile these values with data, we'd expect a reduced risk premia. In this sense, reductions in persistence mitigate the asset-pricing effects of idiosyncratic risk, just as previous work suggests. In a previous version of this paper, for instance, we show that values of $\rho$ in the neighborhood of 0.5 reduce Sharpe ratios by an order of magnitude. High persistence, therefore, is an important part of the story regardless of the cyclical pattern in volatility which the literature has emphasized.

\subsection{Borrowing Constraints}

Unlike many related studies (e.g., Heaton and Lucas (1996), Krusell and Smith (1997), Telmer and Zin (2001)), our model has placed no constraints on borrowing other than the terminal wealth condition. Were we to impose such constraints, not surprisingly, risk premiums in our model would increase. For instance, we find that a borrowing limit equal to $5 \%$ of expected, next-period income increases the Sharpe ratio and equity premium to 51.5 percent and 5.0 percent, respectively. Tightening the constraint to $1 \%$ increases these values further, to 56.3 percent and 5.5 percent. We do impose a short-sales constraint, but find the effects of removing it to be quantitatively very small (a change in the Sharpe ratio of less than 1 percent). Portfolio constraints, therefore, play no role in our model.

\section{Conclusions}

Our main question is whether idiosyncratic labor-market risk matters for the pricing of aggregate risk. An inescapable aspect of idiosyncratic risk is that it necessarily has a life-cycle component: the young face more than the old. This arises both directly - workers face shocks but retirees don't - and indirectly, in terms of the inevitable life-cycle pattern in the ratio of human wealth to total wealth. These life-cycle effects are of first-order importance for the question. They imply that a substantial fraction of the population don't care very much about the very shocks which drive the model, and therefore present a challenge to the asset-pricing story. Nevertheless, our main conclusion is that idiosyncratic risk matters and that life-cycle effects actually strengthen its impact.

What drives our model is an interaction between idiosyncratic and aggregate risk which goes beyond the countercyclical-volatility effect emphasized by Constantinides and Duffie (1996), Mankiw (1986) and many subsequent papers. The converse of the fact that younger agents face the most idiosyncratic risk is that older agents face the most aggregate risk. Idiosyncratic risk is difficult to transfer across generations. Aggregate risk is not. Our framework suggests that how the aggregate risk is shared, 
and how this interacts with the nontradeable distribution of idiosyncratic risk, is important for asset pricing. If, for instance, an equilibrium features equity ownership increasing with age, then the effect of idiosyncratic risk will be diminished relative to the Constantinides and Duffie (1996) model. If equity ownership decreases with age, the opposite will hold. Our calibration generates an intermediate case: equity ownership increases until the late working years and then declines into retirement. The asset pricing effects of idiosyncratic shocks and the countercyclical-volatility effect remain important and our model generates slightly higher risk premia than the infinite-horizon Constantinides and Duffie (1996) model.

More specifically, our model is driven by life-cycle variation in the ratio of human wealth to financial wealth and the fact that idiosyncratic risk affects the former but not the latter. There are two main forces at work. First, as an agent ages, idiosyncratic risk becomes less important to them. This happens both because they face fewer (persistent) shocks in the future and because human wealth declines as a fraction of total wealth. The countercyclical-volatility effect, therefore, becomes less important with age and tolerance for equity-holding increases. Second, because equity returns are substantially more volatile than the wage rate, age also brings with it an increased exposure to aggregate shocks, because an increasing share of an agent's income derives from financial assets instead of human wealth. This effect eventually counteracts the first effect and, late in the working life, tolerance for equity-holding begins to decrease with age. Taken together, the two effects imply that young agents hold zero equity, retired agents hold diversified portfolios of equity and bonds, and middleaged agents hold levered equity, issuing bonds to both the young and the old. The risk premium which supports this allocation reflects both the countercyclical-volatility risk emphasized by Constantinides and Duffie (1996), and a "concentration of aggregate risk" upon the middle-aged, alluded to by Mankiw (1986).

Constantinides, Donaldson, and Mehra (1997) (CDM) also stress the importance of life-cycle effects for the equity premium. Like us, an important feature of their model is that young agents hold zero equity, thereby concentrating aggregate risk on older agents. The reasons, however, are fundamentally different than in our framework, which gives rise to stark, testable restrictions between the two. Our model is distinguished by idiosyncratic risk within generations. A young agent's choice to avoid equity is a portfolio allocation decision: equity is too risky, so they choose not to hold any. In the CDM framework, where heterogeneity only exists across generations, the driving force is consumption smoothing and how it interacts with borrowing constraints. Young agents receive a relatively meager endowment, cannot borrow or short sell equity, and therefore choose not to hold any assets whatsoever. The two models, therefore, offer starkly different interpretations of why one might see a young household choose not to hold equity. The testable restrictions are related to overall savings behavior and how important the precautionary motive is. In our model the average young household is a net saver during the first third of their lives. That is, the precautionary motive dominates the life cycle motive, and the decision to avoid 
equity is driven by risk, in our case an avoidance of the countercyclical volatility risk. The CDM framework is consistent with the same average, young household not accumulating any assets but, in contrast, viewing equity (in a shadow value sense) as an attractive investment. Which of these interpretations is more important - it seems clear to us that the world features aspects of each of them - is something we leave to future work.

Another direction for future work involves enriching our notion of idiosyncratic risk, perhaps in relation to the growing body of work suggesting an important link between private business ownership, portfolio choice and asset pricing (e.g., Gentry and Hubbard (2000), Heaton and Lucas (2000), Polkovnichenko (1999), Quadrini (1999)). While one might interpret our reduced-form process as an amalgamation of the risks faced by both labor and private business owners - i.e., it seems natural that persistence and countercyclical volatility might be an important characteristic of both - it lacks a key aspect of entrepreneurship: the decision to become an entrepreneur, take on the associated risks and bear the associated costs. A better understanding of this decision is likely to enrich our knowledge of how important individual-level risks are for the pricing of aggregate risks. 


\section{References}

Aiyagari, S. R., (1994), Uninsured idiosyncratic risk and aggregate saving, Quarterly Journal of Economics 109, 659-684.

Aiyagari, S. R. and M. Gertler, (1991), Asset returns with transactions costs and uninsured individual risk, Journal of Monetary Economics 27, 311-331.

Altonji, J. G., F. Hayashi, and L. J. Kotlikoff, (1991), Risk sharing, altruism, and the factor structure of consumption, NBER working paper number 3834 .

Altug, S. and R. A. Miller, (1990), Households choices in equilibrium, Econometrica $58,543-70$.

Alvarez, F. and U. Jermann, (1999), Quantitative asset pricing implications of endogeneous solvency constraints, forthcoming, Review of Financial Studies.

Amerkis, J. and S. P. Zeldes, (2000), How do household portfolio shares vary with age?, Unpublished manuscript, Columbia University.

Attanasio, O. and S. J. Davis, (1996), Relative wage movements and the distribution of consumption, Journal of Political Economy 104, 1227-1262.

Attanasio, O. and G. Weber, (1992), Consumption growth and excess sensitivity to income: evidence from U.S. micro data, Unpublished manuscript, Stanford University.

Balduzzi, P. and T. Yao, (2000), Does heterogeneity matter for asset pricing, Unpublished manuscript, Boston College.

Bodie, Z., R. C. Merton, and W. F. Samuelson, (1992), Labor supply flexibility and portfolio choice in a life cycle model, Journal of Economic Dynamics and Control $16,427-49$.

Boldrin, M., L. J. Christiano, and J. D. Fisher, (2001), Habit persistence, asset returns and the business cycle, American Economic Review 91, 149-166.

Brav, A., G. M. Constantinides, and C. Geczy, (2000), Asset pricing with heterogeneous consumers and limited participation: Empirical evidence, Working paper, The Wharton School, University of Pennsylvania.

Brown, D. P., (1990), Age clienteles induced by liquidity constraints, International Economic Review 31, 891-911.

Cochrane, J. H., (1991), A simple test of consumption insurance, Journal of Political Economy 99, 957-76. 
Cogley, T., (2000), Idiosyncratic risk and the equity premium: Evidence from the consumer expenditure survey, forthcoming, Journal of Monetary Economics.

Constantinides, G. M., J. B. Donaldson, and R. Mehra, (1997), Junior can't borrow: a new perspective on the equity premium puzzle, Working paper, University of Chicago, GSB.

Constantinides, G. M. and D. Duffie, (1996), Asset pricing with heterogeneous consumers, Journal of Political Economy 104, 219-240.

Deaton, A. and C. Paxson, (1994), Intertepmoral choice and inequality, Journal of Political Economy 102, 437-467.

den Haan, W., (1994), Heterogeneity, aggregate uncertainty and the short term interest rate: a case study of two solution techniques, Working paper, University of California at San Diego.

den Haan, W., (1997), Solving dynamic models with aggregate shocks and heterogeneous agents, Macroeconomic Dynamics 1, 355-386.

den Haan, W. and A. Marcet, (1994), Accuracy in simulations, Review of Economic Studies 61, 3-17.

Gentry, W. M. and R. G. Hubbard, (2000), Entrepreneurship and household saving, Unpublished manuscript, Columbia University.

Gertler, M., (1999), Government debt and social security in a life cycle economy, Carnegie Rochester Conferance Series on Public Policy 50, 61-110.

Graham, J. R., (2000), How big are the tax benefits of debt?, Journal of Finance 55, 1901-1941.

Greenwood, J., Z. Hercowitz, and G. W. Huffman, (1988), Investment, capacity utilization and the business cycle, American Economic Review 78, 402-18.

Greenwood, J., Z. Hercowitz, and P. Krusell, (1997), Long-run implications of investment-specific technological change, American Economic Review 87, 342362 .

Heaton, J. and D. J. Lucas, (1996), Evaluating the effects of incomplete markets on risk sharing and asset pricing, Journal of Political Economy 104, 443-487.

Heaton, J. and D. J. Lucas, (2000), Portfolio choice and asset prices; the importance of entrepreneurial risk, Journal of Finance 55, 1163-1198.

Huggett, M., (1993), The risk free rate in heterogeneous-agents, incomplete insurance economies, Journal of Economic Dynamics and Control 17, 953-969. 
Huggett, M., (1996), Wealth distribution in life-cycle economies, Journal of Monetary Economics 38, 469-494.

Jagannathan, R. and N. Kocherlakota, (1996), Why should older people invest less in stocks than younger people?, Federal Reserve Bank of Minneapolis, Quarterly Review 20, 11-23.

Krusell, P. and A. A. Smith, (1997), Income and wealth heterogeneity, portfolio choice, and equilibrium asset returns, Macroeconomic Dynamics 1, 387-422.

Krusell, P. and A. A. Smith, (1998), Income and wealth heterogeneity in the macroeconomy, Journal of Political Economy 106, 867-896.

Lucas, D. J., (1994), Asset pricing with undiversifiable risk and short sales constraints: Deepening the equity premium puzzle, Journal of Monetary Economics 34, 325341.

Mace, B. J., (1991), Full insurance in the presence of aggregate uncertainty, Journal of Political Economy 99, 928-56.

Mankiw, N. G., (1986), The equity premium and the concentration of aggregate shocks, Journal of Financial Economics 17, 211-219.

Marcet, A. and K. J. Singleton, (1999), Equilibrium assets prices and savings of heterogeneous agents in the presence of portfolio constraints, Macroeconomic Dynamics $3,243-277$.

Mehra, R. and E. Prescott, (1985), The equity puzzle, Journal of Monetary Economics $15,145-61$.

Polkovnichenko, V., (1999), Heterogeneity and proprietary income risk: implications for stock market participation and asset prices, Manuscript, Northwestern University.

Quadrini, V., (1999), The importance of entrepreneurship for wealth concentration and mobility, The Review of Income and Wealth 45, 1-40.

Ramchand, L., (1999), Asset pricing in international markets in the context of agent heterogeneity and market incompleteness, forthcoming, Journal of International Money and Finance.

Ríos-Rull, J. V., (1994), On the quantitative importance of market completeness, Journal of Monetary Economics 34, 463-496.

Ríos-Rull, J.-V., (1996), Life cycle economies and aggregate fluctuations, Review of Economic Studies 63, 465-489. 
Sarkissian, S., (1999), The cross-country consumption dispersion and the world business cycle, Unpublished manuscript, McGill University.

Storesletten, K., (1999), Sustaining fiscal policy through immigration, forthcoming, Journal of Political Economy.

Storesletten, K., C. I. Telmer, and A. Yaron, (2000a), Consumption and risk sharing over the life cycle, NBER working paper \#7995.

Storesletten, K., C. I. Telmer, and A. Yaron, (2000b), The welfare cost of business cycles revisited: Finite lives and cyclical variation in idiosyncratic risk, forthcoming, European Economic Review.

Storesletten, K., C. I. Telmer, and A. Yaron, (2001), Cyclical dynamics in idiosyncratic labor market risk, Working paper, Carnegie Mellon University.

Telmer, C. I., (1993), Asset pricing puzzles and incomplete markets, Journal of Finance $48,1803-1832$.

Telmer, C. I. and S. E. Zin, (2001), Prices as factors: Approximate aggregation with incomplete markets, forthcoming Journal of Economic Dynamics and Control.

Weil, P., (1992), Equilibrium asset prices with undiversifiable labor income risk, Journal of Economic Dynamics and Control 16, 769-790.

Zhang, H., (1997), Endogenous borrowing constraints with incomplete markets, Journal of Finance 52, 2187-2209. 


\section{A Calibration Appendix}

This appendix first describes the calibration of the no-trade (Constantinides and Duffie (1996)) economies in Section 2 and Table 1, and then goes on to describe the calibration of the economies with trade, presented in Section 3 and Table 1. It also demonstrates the sense in which our specification for countercyclical volatility - heteroskedasticity in the innovations to the idiosyncratic component of log income - is consistent with the approach used by previous authors (e.g., Heaton and Lucas (1996), Constantinides and Duffie (1996)). In each case the cross sectional variance which matters turns out to be the variance of the change in the log of an individual's share of income and/or consumption.

\section{Calibration of No-Trade Economies}

Aggregate consumption growth follows a two-state Markov chain, identical to that in Mehra and Prescott (1985). We parameterize the process using the same values as they did, with the mean, standard deviation and autocorrelation of aggregate consumption growth being $0.018,0.036$, and -0.14 , respectively. The Constantinides and Duffie (1996) model is then 'calibrated' via a re-interpretation of the preference parameters of the Mehra and Prescott (1985) representative agent. Recall that we use $\beta$ and $\gamma$ to denote an individual agent's utility discount factor and risk aversion parameters, respectively. Constantinides and Duffie (1996) construct a representative agent (their equation (16)) whose rate of time preference and coefficient of relative risk aversion are (using our notation),

$$
-\log \beta^{*}=-\log (\beta)-\frac{\gamma(\gamma+1)}{2} a
$$

and

$$
\gamma^{*}=\gamma-\frac{\gamma(\gamma+1)}{2} b
$$

respectively. In these formulae, the parameters $a$ and $b$ relate the cross sectional variance in the change of the $\log$ of individual $i$ 's share of aggregate consumption $\left(y_{t+1}^{2}\right.$, using Constantinides-Duffie's notation) to the growth rate of aggregate consumption:

$$
\operatorname{Var}\left(\log \frac{c_{i, t+1} / c_{t+1}}{c_{i t} / c_{t}}\right)=a+b \log \frac{c_{t+1}}{c_{t}}
$$

All that we require, therefore, are the numerical values for $a$ and $b$ which are implied by our PSID-based estimates in Table 1 of Storesletten, Telmer, and Yaron (2001).

Our estimates are based on income, $y_{i t}$. Because the Constantinides-Duffie model is autarkic, we can interpret these estimates as pertaining to individual consumption, $c_{i t}$. Balduzzi and Yao (2000), Brav, Constantinides, and Geczy (2000), and Cogley 
(2000) take the alternative route and use microeconomic consumption data. While their results are generally supportive of the model, they each point out serious data problems associated with using consumption data. Income data is advantageous is this sense. In addition, our objective is just as much relative as it is absolute. That is, consumption is endogenous in the model of Section 3, driven by risk sharing behavior and the exogenous process for idiosyncratic income risk. What Table 1 asks is, "what would the Constantinides-Duffie economy look like, were its agents to be endowed with idiosyncratic risk of a similar magnitude?" Also, "how does our model measure up, in spite of its non-degenerate (and more realistic) risk sharing technology?" Using income data seems appropriate in this context. For the remainder of this appendix we set $c_{i t}=y_{i t}$.

We need to establish the relationship between our specification for idiosyncratic shocks and the log-shares of aggregate consumption in equation (24). Denote individual $i^{\prime} s$ share at time $t$ as $\gamma_{i t}$, so that,

$$
\log \gamma_{i t} \equiv \log c_{i t}-\log \tilde{E}_{t} c_{i t}
$$

where the notation $\tilde{E}_{t}(\cdot)$ denotes the cross-sectional mean at date $t$, so that $\tilde{E}_{t} c_{i t}$ is date $t$, per-capita aggregate consumption. The empirical specification in Storesletten, Telmer, and Yaron (2001) identifies an idiosyncratic shock as the residual from a log regression with year-dummy variables:

$$
z_{i t}=\log c_{i t}-\tilde{E}_{t} \log c_{i t}
$$

which have a cross-sectional mean of zero, by construction, and a sample mean of zero, by least squares. The difference between our specification and the log-share specification is, therefore,

$$
\begin{aligned}
\log \gamma_{i t}-z_{i t} & =\tilde{E}_{t} \log c_{i t}-\log \tilde{E}_{t} c_{i t} \\
& =\tilde{E}_{t} \log \gamma_{i t}-\log \tilde{E}_{t} \gamma_{i t}
\end{aligned}
$$

The share, $\gamma_{i t}$, is defined so that its cross-sectional mean is always unity. The second term is therefore zero. For the first term, note that in both our economy and the statistical model underlying our estimates, the cross sectional distribution is log normal, conditional on knowledge of current and past aggregate shocks. If some random variable $x$ is $\log$ normal and $E(x)=1$, then $E(\log x)=-\operatorname{Var}(\log x) / 2$. As a result,

$$
\log \gamma_{i t}-z_{i t}=-\frac{1}{2} \tilde{V}_{t}\left(\log \gamma_{i t}\right)
$$

where $\tilde{V}_{t}$ denotes the cross-sectional variance operator. Because lives are finite in our model, and because we interpret data as being generated by finite processes, this crosssectional variance will always be well defined, irrespective whether or not the shocks are unit root processes. 
The quantity of interest in equation (24) can now be written as,

$$
\begin{aligned}
\log \frac{c_{i, t+1} / c_{t+1}}{c_{i t} / c_{t}} & \equiv \log \gamma_{i, t+1}-\log \gamma_{i t} \\
& =z_{i, t+1}-z_{i t}-\frac{1}{2}\left(\tilde{V}_{t+1}\left(\log \gamma_{i, t+1}\right)-\tilde{V}_{t}\left(\log \gamma_{i t}\right)\right)
\end{aligned}
$$

The term in parentheses - the difference in the variances - does not vary in the cross section. Consequently, application of the cross-sectional variance operator to both sides of equation (25) implies,

$$
\tilde{V}_{t+1}\left(\log \frac{c_{i, t+1} / c_{t+1}}{c_{i t} / c_{t}}\right)=\tilde{V}_{t+1}\left(z_{i, t+1}-z_{i t}\right) .
$$

The process underlying our estimates is

$$
z_{i, t+1}-z_{i t}=(1-\rho) z_{i t}+\eta_{i, t+1}
$$

where the variance of $\eta_{i, t+1}$ depends on the aggregate shock. For values of $\rho$ close to unity the variance of changes in $z_{i t}$ is approximately equal to the variance of $\eta_{i, t+1}$. The left side of equation (24) is, therefore, approximately equal to the variance of innovations, $\eta_{i, t+1}$,

$$
\tilde{V}_{t+1}\left(\log \frac{c_{i, t+1} / c_{t+1}}{c_{i t} / c_{t}}\right) \approx \tilde{V}_{t+1}\left(\eta_{i, t+1}\right)
$$

For unit root shocks - which we assume for most of Section 3, this holds exactly. The estimates of $\sigma_{E}$ and $\sigma_{C}$ in Storesletten, Telmer, and Yaron (2001), Table 1, are therefore sufficient to calibrate the Constantinides-Duffie model.

All that remains are to map our estimates into numerical values for $a$ and $b$ from equation (24). Since aggregate consumption growth - the variable on the right side of equation (24) - takes on only two values (3.8 percent and -0.8 percent), computing the parameters $a$ and $b$ simply involves two linear equations:

$$
\begin{aligned}
\sigma_{E}^{2} & =a+0.038 b \\
\sigma_{C}^{2} & =a-0.008 b,
\end{aligned}
$$

Storesletten, Telmer, and Yaron's (2001) estimates are $\sigma_{E}^{2}=0.037$ and $\sigma_{C}^{2}=0.181$. These estimates, however, are associated with $\rho=.92$. For our unit root economies, we scale them down so as to maintain the same average unconditional variance (across age). This results in $\sigma_{E}^{2}=0.0095$ and $\sigma_{C}^{2}=0.0467$. The resulting values for $a$ and $b$ are $a=0.0374$ and $b=-0.5160$. 
The models in Section 3 are calibrated as follows. A period is interpreted as one year. The aggregate shock in equation (16) follows a first-order Markov chain with values $Z \in\{0.9725,1.0275\}$. The unconditional probabilities are 0.5 and the transition probabilities are such that the probability of remaining in the current state is $2 / 3$ (so that the expected duration of a 'business cycle' is 6 years). Capital's share of output, $\theta$ from equation (16), is set to 0.40 , and the average annual depreciation rate, $\delta$, is set to match the average riskfree rate of 1.3 percent. This results in $\delta=0.164$. The average wage rate, $w$, is set equal to $(1-\theta) E(K)^{\theta} N^{-\theta}$. The parameter $s$ is chosen so that the standard deviation of the risky return, $r_{t}$, is 10 percent. The secular growth rate, by which all quantities are normalized, is 1.5 percent.

In Section 3.2, the persistent component of hours worked, $z_{i t}^{h}$, follows a unit root process with innovations governed by a four-state Markov chain, two states corresponding to an expansion and the other two a contraction. The conditional variances, $\sigma_{E}^{2}$ and $\sigma_{C}^{2}$, are set to 0.0095 and 0.0467 respectively, which are taken from Storesletten, Telmer, and Yaron (2001), Table 1, and then scaled down so that the unconditional variance matches that of the $\rho=0.92$ process (a value of 0.0281 ). In the case of meanreverting shocks, we implement their directly, by imposing the following restrictions on the approximated 4-state discrete Markov process: (i) the conditional variance in recessions and booms should be 0.181 and 0.037 , (ii) the autocorrelation should be 0.92 , (iii) the transition matrix $\Gamma$ should be symmetric. It is infeasible to match the autocorrelation exactly, so the Markov chain we use has an autocorrelation of only 0.890 . The elements of the process $z$ are $z \in\{-2.385,0.646\} \equiv\left\{z_{r l}, z_{r h}\right\}$ in recessions and $z \in\{-0.904,0.467\} \equiv\left\{z_{b l}, z_{b h}\right\}$ in booms. The transition matrix is

\begin{tabular}{c|cccc} 
& $\left(z_{r l}^{\prime}\right)$ & $\left(z_{r h}^{\prime}\right)$ & $\left(z_{b l}^{\prime}\right)$ & $\left(z_{b h}^{\prime}\right)$ \\
\hline & & & & \\
$\left(z_{r l}^{\prime}\right)$ & .784 & .016 & .196 & .004 \\
$\left(z_{r h}^{\prime}\right)$ & .016 & .784 & .004 & .196 \\
$\left(z_{b l}^{\prime}\right)$ & .196 & .004 & .784 & .016 \\
$\left(z_{b h}^{\prime}\right)$ & .004 & .196 & .016 & .784
\end{tabular}

The parameters $\kappa_{h}$ are chosen so as to match the PSID mean age profile in earnings.

The demographic structure is calibrated to correspond to several simple properties of the U.S. work force. Agents are 'born' at age 22, retire at age 65 and are dead by age 85. 'Retirement' is defined as having one's labor income drop to zero and having to finance consumption from an existing stock of assets.

Risk aversion is set to match the Sharpe ratio (see Table 1), and the discount factor, $\beta$, is chosen so that the average capital to output ratio generates aggregate consumption variability of 3.7 percent. This results in $\beta=0.69$ and an associated (average) capital to output ratio of 1.8 . 
The following Table illustrates the aggregate properties of our economy. The sample size for the U.S. data is chosen to be the same as that used by Mehra and Prescott (1985)

Table B1: Aggregate Moments

\begin{tabular}{lccc}
\hline \multicolumn{2}{c}{ Panel A: Population Moments of Growth Rates, Theoretical Economy } \\
& Std Dev & Autocorrelation & Correlation with Output \\
& & & \\
& & & \\
Output & 0.930 & -0.307 & 0.998 \\
Investment & 1.214 & -0.309 & 0.935 \\
Consumption & 0.038 & -0.117 & \\
\hline
\end{tabular}

Panel B: Sample Moments of Growth Rates, U.S. Economy, 1929-1982

Std Dev Autocorrelation Correlation with Output

\begin{tabular}{llll}
\hline Output & 0.062 & 0.561 & 1.000 \\
Investment & 0.358 & 0.225 & 0.143 \\
Consumption & 0.036 & 0.353 & 0.471 \\
\hline
\end{tabular}

U.S. sample moments are based on annual NIPA data, 1929-1982. Theoretical moments are computed as sample averages of a long simulated time series.

As is discussed in the text, the production side of our economy is unrealistic. Aggregate consumption variability, however, matches the data, as does the variability of the risky asset return (discussed above). Our model does not resolve the wellknown problems with production-based asset pricing models. It is best viewed in the same way one views any endowment economy: a model with realistic properties of aggregate consumption which can be supported by some, potentially unrealistic, production technology. Alternatively, one can view our economy as featuring a linear technology - commonplace in the finance literature - where we are explicit about the implications of from the production side of the model - not very commonplace in the finance literature. 


\section{B Computational Appendix}

Our general solution strategy follows the work of den Haan (1994), den Haan (1997) and, in particular, Krusell and Smith (1997) and Krusell and Smith (1998). The crucial step is the specification of a finite dimensional vector to represent the law of motion for $\mu$. Given this, each individual faces a finite-horizon dynamic programming problem. The essence of the fixed point problem is the consistency of the law of motion for $\mu$ with the law of motion implied by individual decisions. More specifically, our algorithm involves the following steps.

\section{Algorithm}

1. Approximate the distribution of agents, $\mu$, with a finite number of moments or statistics, $\mu_{m}$. The idea is to capture the information relevant for portfolio decisions in an efficient way as possible. Natural candidates are various moments of individual wealth and bond holdings. Instead, we use aggregate capital and the conditional expected equity premium $\xi_{t}$ as moments. ${ }^{14}$ Note that $\xi_{t}$ is in an agent's period $t$ information set. The seemingly unconventional state variable a conditional price - captures in an efficient way the price information subsumed in a range of equity and bond-holding moments.

2. To solve agent's dynamic programming problem it is necessary to forecast both $\mu_{m}^{\prime}$ and $\xi^{\prime}$. We approximate the agents' expectations for the law of motion of $\mu_{m}$ and $\xi$ by

$$
\left(\mu_{m}^{\prime}, \xi^{\prime}\right)=\hat{G}\left(\mu_{m}, \xi, Z, Z^{\prime}\right)=A\left(Z, Z^{\prime}\right) \times\left(\mu_{m}, \xi\right)
$$

where $A\left(Z, Z^{\prime}\right)$ is an $(m+1) \times(m+1)$ matrix (conditional on $Z$ and $Z^{\prime}$ ), and the entries of $\mu_{m}^{\prime}$ on $\xi$ are zeros (the first $m$ rows of the $m+1$ column). The aggregate shock $Z$ can take on two values, $Z \in\{\underline{Z}, \bar{Z}\}$, so each element in the matrix $A\left(Z, Z^{\prime}\right)$ above can take on four different values. Assume a particular set of values for $A\left(Z, Z^{\prime}\right) \forall Z, Z^{\prime} \in\{\underline{Z}, \bar{Z}\}$.

3. Using the specification above, we solve the following modified version of (21):

$$
\begin{aligned}
& \hat{V}_{h}\left(\xi, \mu_{m}, Z, z, \epsilon, a\right)=\max _{b_{h+1}^{\prime}, k_{h+1}^{\prime}}\left\{u\left(c_{h}\right)+\right. \\
& \left.\quad \beta E\left[\hat{V}_{h+1}^{\prime}\left(\hat{G}\left(\mu, Z, Z^{\prime}\right), Z^{\prime}, z^{\prime}, \epsilon^{\prime}, k_{h+1}^{\prime} \cdot R\left(\hat{G}\left(\mu, Z, Z^{\prime}\right), Z^{\prime}\right)+b_{h+1}^{\prime}\right)\right]\right\}
\end{aligned}
$$

\footnotetext{
${ }^{14}$ The conditional expected equity premium is defined as $\xi_{t} \equiv E_{t}\left\{R_{t+1}\right\}-q_{t}^{-1}$, where $R_{t+1}$ is the return on equity in period $t+1$ and $q_{t}$ is the period $t$ price of a claim that pays one unit of the consumption good in period $t+1$. Note that, given $\xi_{t}$ and conditional expectations over the future states of the world, the implicit bond price is $q_{t}=\left(E_{t}\left\{R_{t+1}\right\}-\xi_{t}\right)^{-1}$. We use $\xi$ because it fluctuates substantially less than $q$, which implies that our approximation of the decision rules become more accurate.
} 
subject to $(20) .{ }^{15}$ The implementation of this is described below.

4. Assume an initial distribution of a large, but finite, number of agents, $\mu$, across wealth, idiosyncratic shocks and age (we use 500 agents in each age cohort). Using the decision rules obtained in (27), simulate a long sequence of the economy (5100 periods) and discard the first 100 periods from this sequence. Note that, for each period in time, $\xi$ must be set so that the bond market clears. That is, find a $\xi^{*}$ such that $\int b_{h}^{\prime}\left(\mu_{m}, \xi^{*}, Z, z, \epsilon, a\right) d \mu=0$.

5. Update $\hat{G}$ by running a linear regression of $\left(\xi^{\prime}, \mu_{m}^{\prime}\right)$ on $\mu_{m}$ from the realized sequence in Step 4. If the coefficients change, use the updated $\hat{G}$ and return to Step 3. Continue this process until convergence.

6. Evaluate the ability of $\hat{G}$ to forecast $\mu_{m}^{\prime}$ and $\xi^{\prime}$. If the goodness of fit is not satisfactory, return to Step 1 and increase the number of moments or change the functional form of $\hat{G}$.

\section{Moments of $\mu_{m}$ and accuracy}

Following Krusell and Smith (1997), we began with just the first moment, aggregate capital, $\mu_{1}=\log (\bar{k})$. This variable has strong predictive power on $\log \left(\bar{k}^{\prime}\right)\left(R^{2}\right.$ of 0.9998), but less predictive power on $\xi^{\prime}$ (see Table C1).

Next, we ask what other moment(s) matter for forecasting $\xi^{\prime}$. To this end, we collected long time series of 18 additional moments of the distribution of agents (see Table C1 for details). Of these, the moments with the largest marginal improvement of forecast accuracy of $\xi^{\prime}$ (over the forecast including only $\log \left(\bar{k}^{\prime}\right)$ ) are the wealth of workers and the fraction of agents constrained in the bond market, which each improve the $R^{2}$ with on average 0.05 and 0.03 , respectively. Including all the 18 moments (together with $\log (\bar{k})$ ) increase the forecast accuracy to 0.994 . Finally, we regressed $\xi^{\prime}$ on $\xi$ and $\log (\bar{k})$, and found that the $R^{2}$ increased to 0.9992 , with a standard deviation of forecast error less than $0.02 \%$ of $\xi$. Hence, $\xi$ provides a better forecast than all the 18 moments together. Our interpretation of this finding is that the the conditional expected equity premium or, equivalently, the bond price, capture a large amount of information relevant for future bond prices. Formally, we could not reject the hypothesis that the residuals from predicting $\left(\mu_{m}^{\prime}, \xi^{\prime}\right)$ by $\hat{G}\left(\mu_{m}, \xi, Z, Z^{\prime}\right)$ are uncorrelated with the 18 variables described above for the simulations we employ.

In summary, we include $\xi$ as an "endogenous" moment in $\mu_{m}$ in order to improve the forecast of $\xi^{\prime}$. Note that, as the value functions explicitly incorporate $\xi$ as a parameter, including $\xi$ in the forecast of $\xi^{\prime}$ come at zero computational cost.

\footnotetext{
${ }^{15}$ Note that in order to ensure that the bond market clears each period, $\xi$ is included as an argument in the value function (Krusell and Smith (1997) use the bond price). One difference from their approach is that, as $\xi$ enters the value function for all age groups, it does not simplify our computations to exclude $\xi^{\prime}$ from next period value functions and rely on "approximate" future market clearing.
} 


\section{Dynamic Programming Problem}

We now describe how the dynamic programming problem in (27) is solved.

1. First, we choose a grid for the continuous variables in the state space. That is, we pick a set of values for $\bar{k}, \xi$, and $a$. The grid points are typically chosen to lie in the stationary region of the state variables and in addition, for wealth, near the borrowing constraint and far in excess of the maximum observed wealth holdings (conditional on age). We pick 11 points for aggregate capital, 11 points for the conditional expected equity premium, and 50 points for individual wealth at each age.

2. Second, we make piecewise linear approximations to the decision rules by solving for portfolio holdings on the grid and iterating on the Euler equations.

This is done in the following way. Given the terminal condition associated with (20), the decision rules of the oldest agents ( $H$ years old) must be $b_{H+1}^{\prime}=k_{H+1}^{\prime}=$ 0 , in any state of the world. That is, the agent consumes all their wealth.

Knowing $c_{H}$, we can in turn compute $b_{H}^{\prime}$ and $k_{H}^{\prime}$ at each grid point using Euler equations of an $H-1$ year old agent (and imposing the borrowing constraints and Kuhn-Tucker conditions):

$$
\begin{aligned}
u_{H-1}^{\prime}\left(c_{H-1}\right) & \geq E\left\{u_{H}^{\prime}\left(c_{H}^{\prime}\right) R^{\prime} \mid \mu_{m}, Z, z, \epsilon\right\} \\
q u_{H-1}^{\prime}\left(c_{H-1}\right) & \geq E\left\{u_{H}^{\prime}\left(c_{H}^{\prime}\right) \mid \mu_{m}, Z, z, \epsilon\right\}
\end{aligned}
$$

Knowing $b_{H}^{\prime}$ and $k_{H}^{\prime}$ at each grid point, we then obtain a piecewise linear approximation of the decision rules by linear interpolation (outside the grid we do linear extrapolation). Computing $c_{H-1}$ is then straightforward, and this procedure is repeated for $H-2$ year old agents and iterated backwards until $h=1$. Note that no further iterations are needed; given the (imperfect) expectations $\hat{G}$ and the decision rules for $h+1$ years old agents, the piecewise approximations are found in one single step for $h$ years old agents.

\section{Accuracy of approximation}

The solutions on the grid points are exact by construction. To evaluate whether the interpolation between grid points gives rise to systematic Euler equation pricing errors we follow den Haan and Marcet (1994) and use simulation to construct the following moment conditions:

$$
g(c, Z, z, R, q) \equiv \frac{1}{T} \sum_{t=1}^{T} \sum_{h=1}^{H} \frac{1}{N_{h}^{*}} \sum_{i=1}^{N_{h}^{*}}\left[\left(\beta\left(\frac{c_{i, t+1}^{h+1}}{c_{i, t}^{h}}\right)^{-\alpha}\left[R_{t+1} \frac{1}{q_{t}}\right]-1\right) \otimes z_{i, t}^{h}\right]
$$

where $T$ is the number of periods in the simulation, $N_{h}^{*}$ is the number of unconstrained agents within age cohort $h$, and the instruments are $z_{i, t}^{h}=\left\{1, a_{i, t}^{h}, R_{t}, R_{f, t-1}\right\}$. We 
calculate the p-value corresponding to the $\chi_{4}^{2}$ statistic based on moment conditions $g(\cdot)$ and its covariance matrix. As in den Haan and Marcet (1994) we repeat this for $S=300$ independent simulations and a sample size of 10000 . The percent of p-values that were above (below) the upper (lower) $5 \%$ critical value were $5.4 \%$ and $(4.1 \%$ ) respectively. By this formal metric the Euler equation errors are quite accurate.

\section{Table C1 Predictability}

\begin{tabular}{|c|c|c|c|c|}
\hline Regressors & \multicolumn{4}{|c|}{$R^{2}$} \\
\hline$\left(Z_{t}=, Z_{t+1}=\right)$ & $(1,1)$ & $(1,2)$ & $(2,1)$ & $(2,2)$ \\
\hline $\log (\bar{k}), \xi$ & .999 & .999 & .999 & .999 \\
\hline $\log (\bar{k})$ & .740 & .907 & .865 & .922 \\
\hline $\log (\bar{k}),\left\{X_{j}\right\}_{j=1}^{6}$ & .842 & .931 & .909 & .941 \\
\hline $\log (\bar{k}),\left\{X_{j}\right\}_{j=1}^{6},\left\{X_{j}^{*}\right\}_{j=1}^{6}$ & .984 & .997 & .996 & .996 \\
\hline $\log (\bar{k}),\left\{X_{j}\right\}_{j=1}^{6},\left\{X_{j}^{*}\right\}_{j=1}^{6},\left\{B_{j}\right\}_{j=2}^{6}$ & .986 & .998 & .997 & .997 \\
\hline $\log (\bar{k}),\left\{X_{j}\right\}_{j=1}^{6},\left\{X_{j}^{*}\right\}_{j=1}^{6},\left\{B_{j}\right\}_{j=2}^{6}, f r_{b t}, f r_{s t}$ & .987 & .998 & .997 & .997 \\
\hline $\log (\bar{k}), X_{1}^{*}$ & .803 & .951 & .922 & .962 \\
\hline $\log (\bar{k}), f r_{b t}$ & .802 & .923 & .898 & .935 \\
\hline
\end{tabular}

$X_{j} \equiv E\left[\left(w_{i t}-E_{t} w_{i t}\right)^{j}\right], w_{i t}$ denotes the wealth of agent $i$ at time $t, X_{j}^{*} \equiv E\left[\left(w_{i t}^{*}-w_{i t}^{*}\right)^{j}\right], w_{i t}^{*}$ denotes the wealth of working agent $i$ at time $t, B_{j} \equiv E\left[\left(b_{i t}-b_{i t}\right)^{j}\right]$, and $b_{i t}$ denotes the bond holdings of agent $i$ at time $t . \quad f r_{b t}$ and $f r_{s t}$ denote the fraction of agents that are constrained in time $t$ at the bond and equity market respectively. The bottom two rows represent the top two individual regressors among all regressors other than $\log (\bar{k})$ and $\xi$. The reported $R^{2}$ are of regressions of $\xi^{\prime}=a\left(Z, Z^{\prime}\right)+X\left(Z, Z^{\prime}\right) * B\left(Z, Z^{\prime}\right)$ 


\section{Table 1 Asset Pricing Properties}

\begin{tabular}{|c|c|c|}
\hline & Riskfree Rate & Equity Premium \\
\hline rs & ea & $\overline{\text { Dev }}$ \\
\hline
\end{tabular}

\begin{tabular}{llllll}
\hline & & & & & \\
U.S. data & 1.30 & 1.88 & 6.85 & 16.64 & 41.17 \\
U.S. data, unlevered & 1.30 & 1.88 & 4.11 & 10.00 & 41.17 \\
& & & & & \\
\hline
\end{tabular}

Models Without Trade (Constantinides-Duffie):

$\begin{array}{lrrrrrr}\text { No Retirement (match SR) } & 9.4 & 1.30 & 11.91 & 13.10 & 31.81 & 41.2 \\ \text { No Retirement (match EP) } & 5.3 & 1.30 & 6.43 & 4.11 & 17.32 & 23.7 \\ \text { Retirement (SR) } & 9.4 & 1.30 & 6.14 & 2.91 & 14.77 & 19.7 \\ \text { Retirement (EP) } & 5.3 & 1.30 & 3.73 & 1.31 & 9.73 & 13.5\end{array}$

Models with Trade:

$\begin{array}{lrrrrrr}\text { Main Model } & 6.7 & 1.30 & 2.79 & 4.21 & 9.71 & 43.3 \\ \text { Homoskedastic Economy } & 6.7 & 3.35 & 3.24 & 1.81 & 9.68 & 18.7 \\ \text { Mean-Reverting } & 6.7 & -0.50 & 3.39 & 4.53 & 8.32 & 54.4 \\ \quad \text { Shocks }(\rho=0.92) & & & & & & \end{array}$

'Models Without Trade' correspond to a calibration of the Constantinides and Duffie (1996) model using the idiosyncratic risk estimates from Storesletten, Telmer, and Yaron (2001), Table 1, and the aggregate consumption moments from Mehra and Prescott (1985). Details are given in Appendix A. In rows labeled 'match SR' and 'match EP,' risk aversion is chosen to match the U.S. Sharpe ratio and the mean equity premium, respectively. Rows labeled 'Retirement' hold risk aversion at these levels and then incorporate retirement, defined as old agents not receiving any idiosyncratic shocks (Section 2.2). Should risk aversion be re-selected to match SR and EP, the implied values are 19.8 and 11.2, respectively. 'Models with Trade,' described in Section 3, enhance the definition of retirement by incorporating life-cycle savings and a life-cycle pattern in the ratio of human to total wealth. Risk aversion in the 'Main Model' is chosen to match the U.S. Sharpe ratio. The 'Homoskedastic Economy' is distinguished by the volatility of idiosyncratic shocks not varying with aggregate shocks. The 'Mean-Reverting' economy reduces the autocorrelation of idiosyncratic shocks to 0.92, holding all other parameter values constant.

U.S. sample moments are computed using non-overlapping annual returns, (end of) January-overJanuary, 1956-1996. Estimates of means and standard deviations are qualitatively similar using annual data beginning from 1927, or a monthly series of overlapping annual returns. Equity data correspond to the annual return on the CRSP value weighted index, inclusive of distributions. Riskfree returns are based on the one month U.S. treasury bill. Nominal returns are deflated using the GDP deflator. All returns are expressed as annual percentages. Unlevered equity returns are computed using a debt to firm value ratio of 40 percent, which is taken from Graham (2000). 


\section{Figure 1}

Mean Portfolio Share in Bonds, by Age

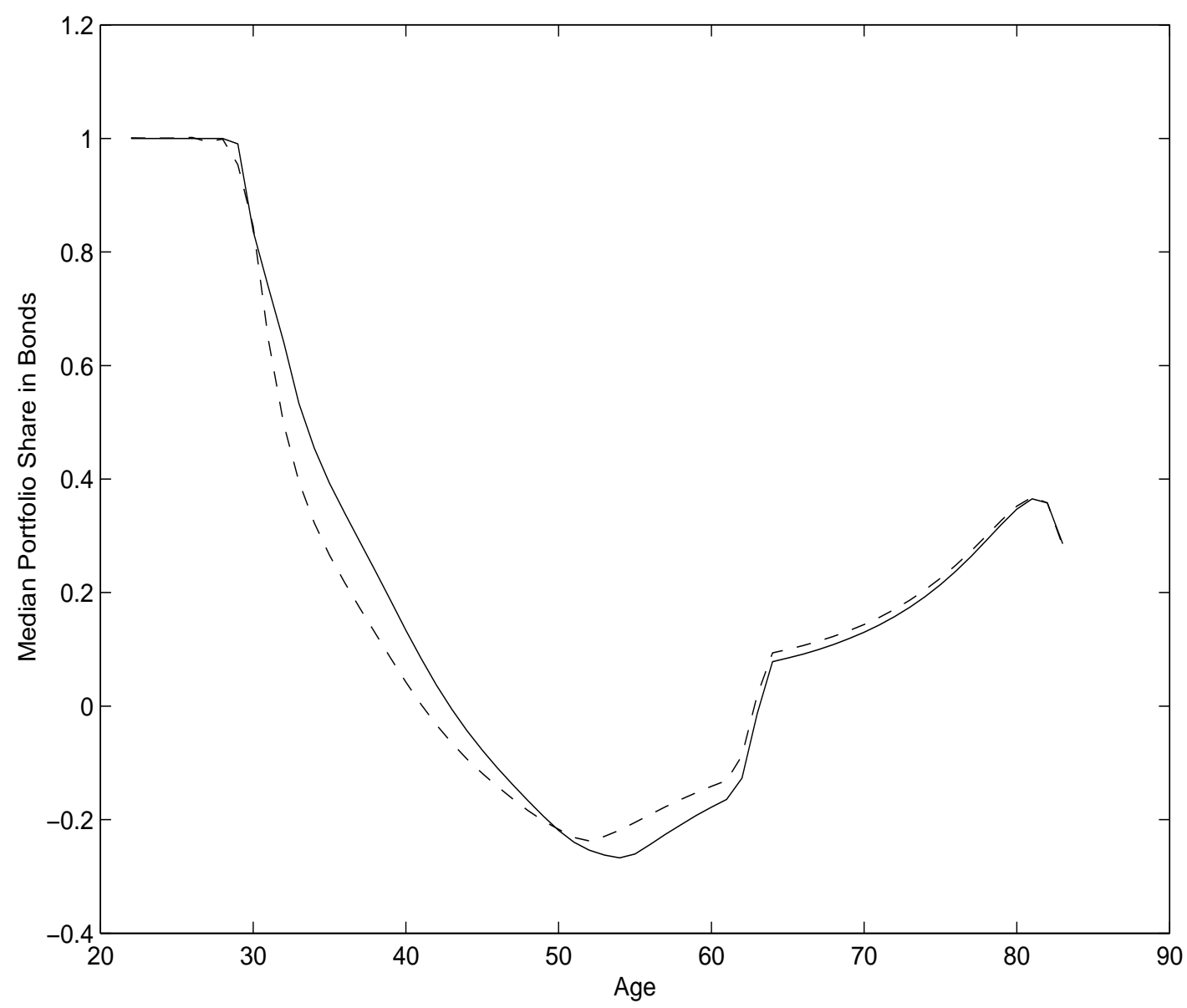

The solid line conditions on aggregate expansions. The dashed line conditions on aggregate contractions. 


\section{Figure 2}

\section{Risk Sharing Behavior}

A: Cross-Sectional Variance of Log Consumption and Income

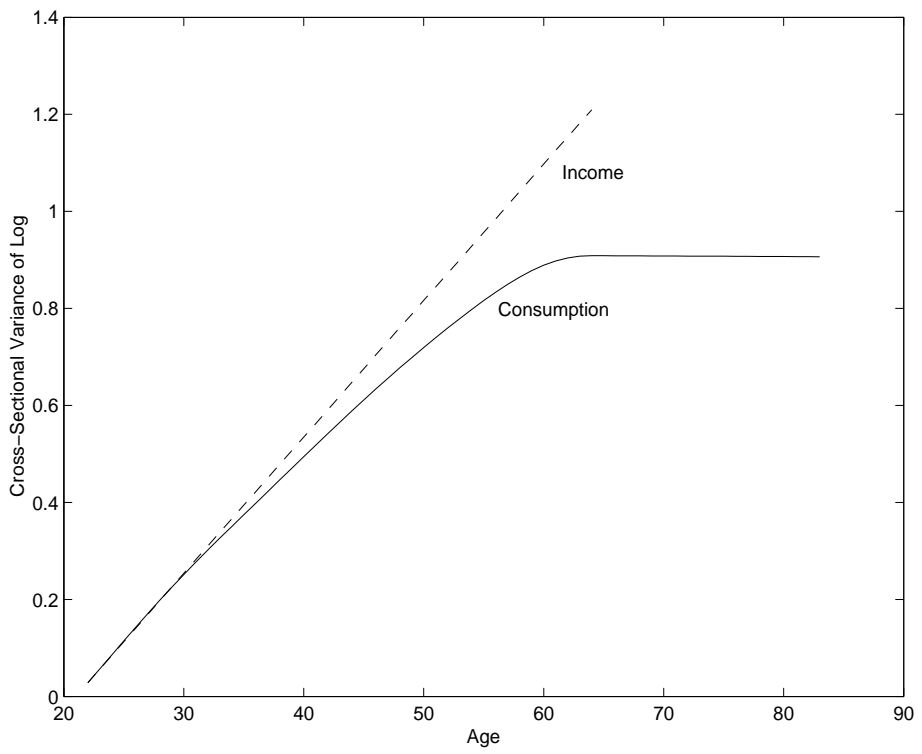

B: Cross-Sectional Standard Deviation of Growth Rates

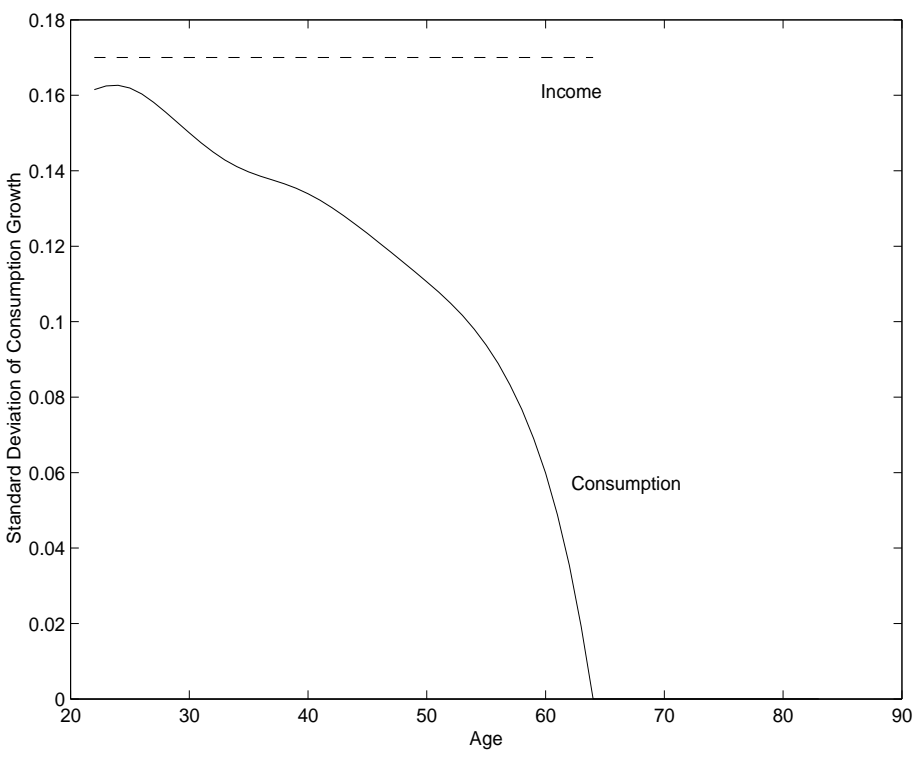

Panel A reports the cross-sectional variance of log consumption and labor income from the economy in Section 3. We report the variance, instead of the more natural standard deviation, because it will be linear, given a unit root process (as is the case for income). Panel B reports the standard deviation of the consumption and income growth rates. 